\title{
Exploring Flexibility, Intermolecular Interactions and Admet Profiles of Anti-influenza Agent Isorhapontigenin: A Quantum Chemical and Molecular Docking Study
}

\section{Sathya Bangaru}

Periyar University

Prasath Manivannan ( $\nabla$ sanprasath2006@gmail.com )

Periyar University PG Extension Centre

Sivakumar Murugesan

Periyar University PG Extension Centre

Govindammal Madhu

Periyar University PG Extension Centre

\section{Research Article}

Keywords: FT-IR, FT-Raman, UV-Vis, ADMET, Influenza

Posted Date: March 16th, 2021

DOl: https://doi.org/10.21203/rs.3.rs-287191/v1

License: (c) (i) This work is licensed under a Creative Commons Attribution 4.0 International License.

Read Full License 


\title{
Exploring flexibility, intermolecular interactions and ADMET profiles of anti-influenza agent Isorhapontigenin: A quantum chemical and molecular docking study
}

\author{
Sathya Bangaru ${ }^{1}$ Prasath Manivannan ${ }^{1, *} \cdot$ Sivakumar Murugesan ${ }^{1}$. \\ Govindammal Madhu' ${ }^{1}$ \\ ${ }^{1}$ Department of Physics, Periyar University PG Extension Centre, Dharmapuri, 636 701, \\ Tamilnadu, India \\ *Corresponding author: sanprasath2006@ gmail.com (Dr. M. Prasath)
}

Contact No: 9942922455 


\begin{abstract}
Isorhapontigenin (IRPG) drug emerges as promising efficient inhibitor for H1N1 and H3N2 subtypes which belong to influenza A virus; reported with $\mathrm{IC}_{50}$ value of 35.62 and $63.50 \mu M$ respectively. The computed geometrical parameters and vibrational assignments (FT-IR and FT-Raman) are compared with experimental results, these results exhibits good correlation with each other. UV-Vis electronic property reveals that the absorption bands of $\pi \rightarrow \pi^{*}$ transitions, this authorizes that the bands are very strong in the IRPG molecule. The kinetic stability and chemical reactivity of the IRPG molecule was probed through NBO and HOMO-LUMO analysis. Electrophilic and nucleophilic site selectivity of IRPG was explored through MEP map and Fukui function. In molecular docking analysis, the IRPG molecule exhibits the better inhibition constant and binding affinity for H1N1 and H3N2 influenza virus. As a result, the IRPG molecule exposes virtuous biological deeds in nature and it can be performed as a prospective drug candidate for $\mathrm{H} 1 \mathrm{~N} 1$ and $\mathrm{H} 3 \mathrm{~N} 2$ viral A influenza.
\end{abstract}

Keywords FT-IR $\cdot$ FT-Raman $\cdot$ UV-Vis $\cdot$ ADMET $\cdot$ Influenza

\title{
Introduction
}

Since overall scourge strains and yearly pandemic, Influenza can cause an intense respiratory ailment [1] caused by RNA virus which belongs to the Orthomyxoviridae family [2]. As the mortality and morbidity rate caused by influenza virus is very high, it crafts severe consequences throughout the world [3-8]. Influenza contains two glycoproteins specially; Hemagglutinin (HA) [9] and Neuraminidase (NA) [10] based on this influenza A is branched into subgroups. Consequently HA as 18 subcategories and NA as 11 subcategories, in this subtypes $\mathrm{H} 1 \mathrm{~N} 1$ and $\mathrm{H} 3 \mathrm{~N} 2$ are endemic in humans [11-12]. HA was a cellanchoring viral glycoprotein which is responsible for viral infection via linking monosaccharide sialic acid having receptors on the host cells and mediating the entry and fusion of virus [13]. NA (sialidase) is a hydrolytic viral glycoprotein which is feasible for cleaving of sialic acid from surface of the cell and also to release the progeny virus particles from host cells [14]. Hence the viral NA enzyme has been a functioning exploration territory against anti-influenza treatment due to release of virus particles from host cells. For the vast majority, influenza settles on its own, but in some cases its complications can be treacherous. In this sense there is a need of proceeding requirement for advancement of new anti-influenza drugs. 
Presently, most of the research experts progress fewer generic effect plant derivative antiviral drugs to treat influenza virus. Isorhapontigenin (IRPG) is an isomer of rhapontigenin derived from Chinese herb Gnetum cleistostachyum [15] which belongs to the family Gnetaceae and also from some wine grapes. The IRPG possess stilbenoid structure with four hydroxyl groups and one methoxy group attached to it. IRPG was recognized as inhibitor of $\mathrm{H} 1 \mathrm{~N} 1$ and $\mathrm{H} 3 \mathrm{~N} 2$ subcategories which belongs to influenza A virus. IRPG targets were reported to inhibit H1N1 and H3N2 NA enzymes with $\mathrm{IC}_{50}$ value of 35.62 and $63.50 \mu M$ [16] respectively.

As IRPG has extraordinary pharmaceutical application in treating influenza, an endeavor has been made to examine its molecular properties. A complete literature survey has been done and it is found that so far either spectroscopic investigations or molecular docking studies have not been reported. Hence this research investigation has been performed by means of DFT/B3LYP method with $6-311 \mathrm{G}(\mathrm{d}, \mathrm{p})$ and 6-31G(d,p) basis set to study various spectroscopic and biological properties of IRPG. The calculated spectroscopic data (FT-IR and FT-Raman) supported by potential energy distribution were compared with experimentally recorded values. Electronic (UV-Vis) spectral analysis were recorded and compared with theoretically predicted spectra computed through TD-DFT method. Global reactivity descriptors were determined with the help of frontier molecular energies. Molecular electrostatic potential map is analyzed to find the reactive sites of the molecule. Fukui function has been employed to find the electron density of the title compound. NBO analysis is done to find the properties of electronic structure. A molecular docking, druglikeness and ADMET predictions are used to analyse the drug behavior in nature and NA active site cavity. The actual research is very essential for the drug improvement to explore the feasible drug candidate for anti-viral agent against H1N1 and H3N2 influenza viral contagion.

\section{Materials and methods}

\section{Experimental details}

The material IRPG was acquired from Tokyo chemical industry (TCI) chemical company (purity of $>95.0 \%$ ) and exploit without any other purification for the spectral measurements. FT-IR spectrometer (Bruker Tensor 27) was utilized to trace the FT-IR spectrum of the IRPG in the range of $400-4000 \mathrm{~cm}^{-1}$ (4 $\mathrm{cm}^{-1}$ resolution) through the KBr pellet technique. Bruker RFS 27 FT-Raman Spectrophotometer (1064 $n m$ Nd: YAG laser source) was employed to trace the FT-Raman spectrum of the IRPG in the region of 
$400-4000 \mathrm{~cm}^{-1}$. The ultraviolet-visible-NIR (UV-vis-NIR) spectrum of the IRPG was recorded with a UVvis spectrophotometer (UV-2501, Shimadzu Corp., Japan) in the array among 200 and $900 \mathrm{~nm}$.

\section{Computational details}

IRPG molecule was optimized through DFT method via Gaussian09W software program package [17]. IRPG geometrical parameters were conquered via Gauss view 5.0 software [18]. Using VEDA 4xx program package [19] the vibrational assignments for IRPG was requiring through an average of potential energy distribution percentage (PED \%). Further, the potential cube file engendered in Gaussian09W software [17] was embraced for the generation of MEP map of the IRPG molecule via WinXPRO software [20]. Moreover, the electronic properties (UV absorption, HOMO and LUMO) of IRPG molecule were indicated through TD-DFT method [21-23] accomplished in Gaussian 09W software [17]. Second order Fock matrix which regulates the donor-acceptor interactions of IRPG was computed via NBO 3.1 program [24]. Molecular docking exploration was executed with AutoDock4.2 software package [25] and their interactions amid IRPG ligand molecule and NA enzyme were determined through Discovery Studio [26], Chimera [27], PyMOL [28] and Ligplot [29] software programmes.

\section{Results and discussion}

\section{Geometry analysis}

Geometrical parameters like bond lengths and bond angles of IRPG molecule is computed through DFT (B3LYP level of theory) method [30,31] with basis sets $(6-31 \mathrm{G}(\mathrm{d}, \mathrm{p})$ and $6-311 \mathrm{G}(\mathrm{d}, \mathrm{p}))$ and the optimized scaled ball and stick model structure is shown in Fig. 1. IRPG molecule was converged at the threshold limits of maximum force (0.000023 a.u.) and displacement (0.001240 a.u.) whereas the gradient of potential energy surface was converged with the RMS gradient value $(0.000307$ a.u.), and also the dipole moment value is found to be 2.2865 Debye. The computed structural parameters of IRPG molecule were compared with experimental XRD data [32] related to the structure because IRPG crystal structure is not published so far based on literature survey and the parameter values are listed in Table 1 . The experimental values varies slightly with computed values for IRPG molecule, which is due to fact that the experimental values are analysed in solid phase and computed values are analysed in gas phase. IRPG affirms that eleven $\mathrm{C}-\mathrm{H}$, fifteen $\mathrm{C}-\mathrm{C}$, five $\mathrm{C}-\mathrm{O}$ and three $\mathrm{O}-\mathrm{H}$ bond lengths respectively. 
In IRPG molecule, the resorcinol ring $\mathrm{C}-\mathrm{C}$ bond lengths ranges from 1.366 to $1.407 \AA$. The hydroxyl groups $(\mathrm{O}-\mathrm{H})$ present in resorcinol ring is $\mathrm{O}(8)-\mathrm{H}(24)$ and $\mathrm{O}(7)-\mathrm{H}(23)$ the values are found to be $0.966 / 0.963 / 0.900 * \AA$ and $0.966 / 0.963 / 0.920 * \AA$ respectively (* specifies the experimental value). The hydroxyl group present in $2^{\text {nd }}$ ring is $\mathrm{O}(19)-\mathrm{H}(33)$ and the value is $0.970 / 0.967 / 0.880 * \AA$. In the bond angles, $C(5)-C(9)-C(10)$ and $C(9)-C(10)-C(11)$ are the highest bond angles values present in IRPG molecule. Due to same charges the $\mathrm{C}-\mathrm{C}$ homonuclear bond length correlates to repulsive and owing to opposite charges, the $\mathrm{C}-\mathrm{H}, \mathrm{C}-\mathrm{O}$ and $\mathrm{O}-\mathrm{H}$ hetronuclear bond lengths correlates to attraction. Moreover, the hetronuclear is smaller when compare to homonuclear bonds [33]. Consequently, these geometrical data imply a good approximation with experimental crystal data and the values are appropriate crucial for computing vibrational frequencies.

\section{Vibrational frequency analysis}

Computed vibrational frequencies (FT-IR and FT-Raman) for IRPG molecule were investigated through DFT method with the basis sets 6-31G(d,p) and 6-311G(d,p) which are scaled down by scaling factors (0.961 and 0.967) [34] along with their PED\% analysed via VEDA 4xx software program [19]. The experimental data are compared with theoretically analyzed data and the values are in noble agreement with the basis set 6-311G(d,p) which is owing to allotment of Gaussian type orbitals (GTOs) for absolutely describing the $\mathrm{H}, \mathrm{O}$ and $\mathrm{C}$ atoms. IRPG molecule possess $\mathrm{C} 1$ point symmetry group which is more stable and it consists of 33 atoms with 93 vibrational modes. Table 2 represents the IR intensities, Raman intensities, vibrational assignments for IRPG. Figs. 2 and 3 display the experimental and theoretical FT-IR and FT-Raman spectra for IRPG molecule.

\section{Hydroxyl (O-H) vibrations}

Owing to intra or inter molecular hydrogen bonding in the molecule, the $\mathrm{O}-\mathrm{H}$ stretching vibrations are highly sensitive which reveals a huge variation in intensity, bandwidth and wavenumber. $\mathrm{O}-\mathrm{H}$ stretching vibrations commonly occur in the region of 3600-3200 $\mathrm{cm}^{-1}$ (while H-bonded) and 3700-3500 $\mathrm{cm}^{-1}$ (while stretch free) [35]. In IRPG molecule the theoretical wavelength are observed at 3676, 3675 and $3620 \mathrm{~cm}^{-1}$ for $6-31 \mathrm{G}(\mathrm{d}, \mathrm{p})$ and 3708,3707 and $3648 \mathrm{~cm}^{-1}$ for $6-311 \mathrm{G}(\mathrm{d}, \mathrm{p})$ with a PED contributions of 96 , 96 and $100 \%$ respectively. Experimental values for IRPG molecule was observed at $3367 \mathrm{~cm}^{-1}$ in FT-IR. 


\section{C-H Vibrations}

The C-H Vibrations frequently occurs in the region of 3100 to $3000 \mathrm{~cm}^{-1}$ for strong Raman peaks [36]. In IRPG molecule the vibrations occur in the region of 3107, 3091, 3080, 3076, 3058, 3043, 3037, 3030, 3028, 2966, $2904 \mathrm{~cm}^{-1}$ for 6-31G(d,p) and 3105, 3092, 3082, 3078, 3061, 3046, 3040, 3033, 3030, 2966, $2908 \mathrm{~cm}^{-1}$ for 6-311G(d,p). The experimental values are observed at 3020, $2937 \mathrm{~cm}^{-1}$ for FT-IR and $3071 \mathrm{~cm}^{-1}$ for FT-Raman. The experimental values are in good agreement with theoretical 6-311G(d,p) values.

\section{Carbonyl (C-O) vibrations}

The $\mathrm{C}=\mathrm{O}$ stretching vibration of $\mathrm{COOH}$ group is exactly matched with the $\mathrm{C}=\mathrm{O}$ stretch in ketones, which is estimated in the region 1740-1660 $\mathrm{cm}^{-1}$ [37]. The $\mathrm{C}-\mathrm{O}$ stretching vibrations are predictable in the range from 1300-1000 $\mathrm{cm}^{-1}$ [38]. In IRPG molecule C-O stretching vibrations appears in the region of 1015 $\mathrm{cm}^{-1}$ for FT-IR and 1120, 1010, $996 \mathrm{~cm}^{-1}$ for FT-Raman. The theoretical values are observed in the region of $1119,1029,995,979,917 \mathrm{~cm}^{-1}$ for 6-31G(d,p) and 1116, 1026, 994, 978, $917 \mathrm{~cm}^{-1}$ for 6-311G(d,p).

\section{C-C vibrations}

$\mathrm{C}-\mathrm{C}$ vibrational bands stimulate the aromatic and hetero aromatic modes in the range of 1650$1400 \mathrm{~cm}^{-1}$ [39] and C-C ring stretching vibrations are anticipated within the region of $1300-1000 \mathrm{~cm}^{-1}$ [40]. The C-C vibrations are reported at 1635, 1594, 1345, 1309, 1148, $781 \mathrm{~cm}^{-1}$ for FT-Raman and 1607, 1373 $\mathrm{cm}^{-1}$ for FT-IR in IRPG molecule. The theoretical values are observed in the range of 1637 to $791 \mathrm{~cm}^{-1}$ in 6-31G(d,p) and 1633 to $793 \mathrm{~cm}^{-1}$ in 6-311G(d,p).

\section{Molecular electrostatic potential (MEP)}

MEP map clearly conveys about the necessary properties (electron density, reactivity, electrophilic sites, nucleophilic sites and further to determine the $\mathrm{H}$ bonding interaction among NA enzyme and IRPG) of drugs and biomolecules. Moreover in MEP map the positive region contribute to electrophilic sites (resembles to higher electron density) and the negative region contribute to nucleophilic sites (resembles to lower electron density) [41-43]. Based on Mulliken atomic charges the MEP map for IRPG is coloured and Mulliken sketch was given identical to MEP as exposed in Fig. 4. Furthermore, nucleophilic and electrophilic sites for IRPG are signified in the increasing electron density order of 
red<orange<yellow<green<sky-blue<blue. The MEP map colour code for IRPG molecule is in the range among $-6.225 \times 10^{-2}$ (orange and deepest red) to $6.225 \times 10^{-2}$ (sky blue and deepest blue). The orange to deepest red colour indicates positive electrostatic potential, sky blue to deepest blue indicates negative electrostatic potential and green colour indicates neutral charge for IRPG molecule. Fig. 5 expose the iso surface representation of IRPG molecule and the values are positive potential at $0.8 e \AA^{-1}$ and negative potential at $0.08 e \AA^{-1}$. The $\mathrm{H}$ and $\mathrm{C}$ atom possess blue colour (electrophilic region) while $\mathrm{O}$ atom possess red colour (nucleophilic region). In IRPG molecule the negative region is more concentrated over $O(7)$, $\mathrm{O}(8), \mathrm{O}(17)$ and $\mathrm{O}(19)$ atom and further these $\mathrm{O}$ atom present in Mulliken sketch also possess negative region. This graphical representation evidently affirms that the MEP and Mulliken charges are parallel.

\section{Electronic transition analysis}

The nature of electronic transition properties for IRPG molecule was analysed through UV-Vis absorption spectra, this transition takes place from HOMO to LUMO level and this was absorbed by bonding $(\pi, \sigma)$, anti-bonding $\left(\pi^{*}, \sigma^{*}\right)$ and non-bonding $(\mathrm{n})$. The theoretical spectrum of IRPG molecule was computed through TD-DFT approach $(6-311 \mathrm{G}(\mathrm{d}, \mathrm{p})$ basis set) using DMSO as a solvent and this values are compared with experimental values. Table 3 exposes the electronic properties of IRPG molecule. The experimental and theoretical spectra of IRPG molecule as displayed in Fig. 6. The strong and weak bands were confirmed through UV absorptions bands of $\pi \rightarrow \pi^{*}$ and $n \rightarrow \pi^{*}$ transitions [44-47]. The $\pi \rightarrow \pi^{*}$ electronic transition bands of IRPG molecule was experimentally observed at 333, 307 and $282 \mathrm{~nm}$ and theoretically observed at 349, 311 and $288 \mathrm{~nm}$, these values are closely reliable with each other. Subsequently, this transition clearly says about the strong interaction among IRPG and DMSO solvent which reveals the biological nature of the IRPG molecule.

\section{Global reactivity descriptors}

Kinetic stability, chemical reactivity and toxicity of the drug molecule are analysed through HOMO and LUMO energies. HOMO energy behaves as a nucleophilic character (electron donation) and LUMO energy behaves as an electrophilic character (electron acceptance). The global reactivity descriptors such as ionization potential $\left(\mathrm{I}=-\mathrm{E}_{\mathrm{HOMO}}\right)$, electron affinity $\left(\mathrm{A}=-\mathrm{E}_{\mathrm{LUMO}}\right)$, global hardness $(\eta=(\mathrm{I}-\mathrm{A}) / 2)$, chemical softness $(s=1 / 2 \eta)$, electronegativity $(\chi=(I+A) / 2)$, chemical potential $(\mu=-\chi)$ and electrophilicity 
$\left(\omega=\mu^{2} / 2 \eta\right)$ were computed for IRPG molecule and listed in Table 4. HOMO and LUMO energies of IRPG molecule is revealed in Fig. 7.

The energy difference between the molecular orbitals (HOMO and LUMO) is known as band gap energy, whereas the molecule which has large energy gap means it is hard molecule and small energy gap means it is soft molecule [44-48]. The band gap energy for IRPG molecule is found to be $3.859 \mathrm{eV}$ which implies that IRPG is soft molecule. The Koopmans's theorem [49] for closed shell molecules states that the ionization potential (change of energy of a system when an electron is removed) and electron affinity (variation of energy of a system when an electron is added) of the molecule. The ionization potential resembles the negative of HOMO energy is found to be $5.368 \mathrm{eV}$ and the electron affinity resembles the negative of LUMO energy is found to be $1.508 \mathrm{eV}$. Pauling and Mulliken [50-52] describes the electronegativity (measure the tendency to attract electrons through an atom in a covalent bond) to determine the electron density of the molecule and the value is found to be $3.438 \mathrm{eV}$. The computed value of ionization potential value is very high when compared to electron affinity and electronegativity; therefore the molecule has fewer tendencies to accept electrons.

Parr and Pearson [52] formulated the global hardness of the molecule which describes the absolute hardness, kinetic stability and reactivity. Global hardness value for IRPG is found to be $1.929 \mathrm{eV}$; this affirms that the molecule has more kinetic stability and reactivity. Chemical softness reveals the reactivity of the molecule and the value for IRPG is found to be $0.259 \mathrm{eV}$. Parr et al. [53] proposed the conception of electrophilicity index [54] to expose the reactivity and toxicity nature [55] of the molecule and the value for IRPG is found to be $3.062 \mathrm{eV}$, this reveals that the molecule has low toxicity. Therefore these results exhibit that the IRPG molecule has good biological behavior in pharmacological properties and drug design.

\section{Local reactivity descriptors}

Local reactivity descriptors, also known as Fukui function plays a vital role in designing the pharmaceutical compounds and drugs to expose the chemical reactivity and site selectivity [56,57]. The Fukui function is based on electron density when some electrons are accepting or donating from it and this helps to predict the electrophilic and nucleophilic attack. The charge distribution between the atoms inside the molecule is predicted through Mulliken population analysis; the charge may be positive or negative depending 
on the number of neighboring atoms. Fig. 8 shows the histogram of computed Mulliken charge of IRPG molecule expect hydrogen atoms. Fukui function, local softness and local electrophilicity index can be expressed as

$\left.\begin{array}{l}f_{\mathrm{k}}{ }^{+}=\left[q_{(\mathrm{N}+1)-} q_{(\mathrm{N})}\right] \text { for nucleophilic attack } \\ f_{\mathrm{k}}^{-}=\left[q_{(\mathrm{N})}-q_{(\mathrm{N}-1)}\right] \text { for electrophilic attack }\end{array}\right\}$ Fukui functions

$\mathrm{s}_{\mathrm{k}}{ }^{+}=(\mathrm{s} f)_{\mathrm{k}}{ }^{+}$and $\mathrm{s}_{\mathrm{k}}^{-}=(\mathrm{s} f)_{\mathrm{k}}{ }^{-}$for local softness

$\omega_{\mathrm{k}}{ }^{+}=(\omega f)_{\mathrm{k}}{ }^{+}$and $\omega_{\mathrm{k}}{ }^{-}=(\omega f)_{\mathrm{k}}{ }^{-}$for local electrophility index

The Fukui function is calculated on the origin of Mulliken atomic charges for cation $(\mathrm{N}+1)$, anion $(\mathrm{N}-1)$ and neutral (N) states for selected atomic sites of IRPG molecule are listed in Table 5 . The $f_{\mathrm{k}}{ }^{+}$and $f_{\mathrm{k}}{ }^{-}$values impels to nucleophilic attack and electrophilic attack respectively. The $f_{\mathrm{k}}{ }^{+}$possess the possible nucleophilic reactivity sites is in the increasing order of $07<019<017<018$ while $f_{\mathrm{k}}{ }^{-}$possess electrophilic reactivity sites is in the increasing order of $\mathrm{C} 6<\mathrm{C} 4$. This result shows that the IRPG molecule has high reactive in nature.

\section{Natural bond orbital's (NBO's)}

The intra and inter molecular interactions within the complex, charge transfer and stabilization energy of molecular systems are analysed through NBO analysis. The stabilization energy of the system which reveals the delocalization of electron density from Lewis type of NBO's (donor orbital (i)) to virtual Rydberg non-Lewis type of NBO's (acceptor orbital (j)) via second order Fock matrix with hyper conjugative interactions [58] and it can be predictable with the subsequent equation.

$E(2)=\Delta E_{i j}=\frac{q_{i}\left(F_{i j}\right)^{2}}{\varepsilon_{j}-\varepsilon_{i}}$

Where, $q_{i}, F_{i j}$ and $\varepsilon_{i},{ }_{j}$ are the donor orbital occupancy, Fock matrix element between $\mathrm{i}$ and $\mathrm{j}$ NBO orbitals and orbital energies of diagonal element, respectively. The possible interactions for IRPG molecule are $\pi \rightarrow \pi^{*}$ and $\mathrm{LP} \rightarrow \pi^{*}$ and listed in Table 6 . For IRPG molecule the delocalization of $\pi \rightarrow \pi^{*}$ interactions of $\pi(\mathrm{C} 1-\mathrm{C} 2) \rightarrow \pi^{*}(\mathrm{C} 3-\mathrm{C} 4), \pi(\mathrm{C} 3-\mathrm{C} 4) \rightarrow \pi^{*}(\mathrm{C} 5-\mathrm{C} 6), \pi(\mathrm{C} 5-\mathrm{C} 6) \rightarrow \pi^{*}(\mathrm{C} 1-\mathrm{C} 2), \pi(\mathrm{C} 11-\mathrm{C} 16) \rightarrow \pi^{*}(\mathrm{C} 14-$ 
$\mathrm{C} 15), \pi(\mathrm{C} 14-\mathrm{C} 15) \rightarrow \pi^{*}(\mathrm{C} 11-\mathrm{C} 16), \pi(\mathrm{C} 14-\mathrm{C} 15) \rightarrow \pi^{*}(\mathrm{C} 12-\mathrm{C} 13)$ with high stabilization energy contributions of $26.36,24.73,26.28,20.44,20.8$ and $20.03 \mathrm{~kJ} / \mathrm{mol}$ respectively. The $\mathrm{LP}(2)$ of oxygen atom interacts with $\pi^{*}$ are $\mathrm{LP}(2) \mathrm{O} 7 \rightarrow \pi^{*}(\mathrm{C} 1-\mathrm{C} 2), \mathrm{LP}(2) \mathrm{O} 8 \rightarrow \pi^{*}(\mathrm{C} 3-\mathrm{C} 4), \mathrm{LP}(2) \mathrm{O} 17 \rightarrow \pi^{*}(\mathrm{C} 12-\mathrm{C} 13)$, $\mathrm{LP}(2) \mathrm{O} 19 \rightarrow \pi^{*}(\mathrm{C} 14-\mathrm{C} 15)$ and the values are $28.39,29.09,26.40$ and $28.82 \mathrm{~kJ} / \mathrm{mol}$ respectively. Moreover, this result shows that IRPG molecule possess high stabilization energy.

\section{Druglikeness properties}

Lipinski's rule of five [59] is formulated by Christopher A. Lipinski to predict the biological activities or pharmacological properties for chemical compound that would make a probable orally drugs in humans. In this work the druglikeness parameters for IRPG molecule were predicted through Molinspiration cheminformatics program (https://www.molinspiration.com). The computed druglikeness values are listed in Table 7 . The orally active drugs must obey the following criteria, the $\mathrm{H}$ bond donors ( $\mathrm{OH}$ and $\mathrm{NH}$ groups) are not more than 5 (IRPG holds 3), the $\mathrm{H}$ bond acceptors $(\mathrm{N}$ and $\mathrm{O}$ ) are not more than $10(2 * 5)$ (IRPG holds 4 ), the octanol-water partition coefficient or High lipophilicity log p is less than or equal to 5 (IRPG holds 2.80), the molecular weight of the molecule is under $500 \mathrm{~g} / \mathrm{mol}$ (IRPG holds $258.27 \mathrm{~g} / \mathrm{mol}$ ), van der Waals bumps topological polar surface area is less than $140 \AA^{2}$ (IRPG holds 69.92 $\AA^{2}$ ) and number of rotatable bonds is less than 10 (IRPG holds 3) [60]. Hence the molecule IRPG obeys the Lipinski's rule of five, this reveals that the bioavailability is good and it is confirmed as suitable oral drug candidate for humans.

The bioactivity score for IRPG molecule is predicted from molinspiration and represented in Table 8. The probability of bioactivity score for average organic molecules exposes that the value greater than 0.00 resembles it is active, if -0.50 to 0.00 shows that it is moderately active and the score less than -0.50 exposes that the molecule is biologically inactive. The nuclear receptor ligand and enzyme inhibitor are found to be 0.04 and 0.02 respectively, this data confirms that the molecule is active. The GPCR ligand, ion channel modulator, kinase inhibitor and protease inhibitor for IRPG holds $-0.13,-0.05,-0.08$ and -0.37 respectively, this values reveals that the molecule moderately active. From this result the IRPG molecule does not fall under the value less than -0.05 , consequently the molecule IRPG is a potential candidate for biological applications and hence utilized for docking analysis. 


\section{ADMET predictions}

The experimental pharmacokinetic and toxicity parameters such as absorption, distribution, metabolism, excretion and toxicity (ADMET) [61,62] predicting is of very high risk due to lengthy process at different stages with unexpected failures in drug discovery and high cost. Consequently, this ADMET is predicted theoretically through web-based platform called PreADMET tools (https://preadmet.bmdrc.kr/) which saves time and investment. Table 9 exposes the theoretically predicted ADMET profiles for IRPG molecule. BBB penetration potential value for IRPG molecule is found to be 0.560014 , this indicates that the molecule can cause fewer side effects in the central nervous system. The normal HIA value 70 to $100 \%$ specifies excellent intestinal absorption for drug molecules are absorbed from the intestine into the blood stream in case of IRPG the value was found to be $88.446064 \%$. The skin permeability value for IRPG is $3.39671 \mathrm{~cm} / \mathrm{h}$, this value shows that the molecule is not absorbed by skin. Caco-2 cell and MDCK cell permeability reveals that oral absorption of drug molecules and the values for IRPG are found to be 4.89208 and $237.503 \mathrm{~nm} / \mathrm{s}$ respectively, this shows that the molecule are easy to absorb. The water solubility in buffer and pure water solubility for IRPG has attained higher values, which are 40.1042 and $124.957 \mathrm{mg} / \mathrm{L}$ respectively. Ames TA100 (+S9), Ames TA100 (-S9), Ames TA1535 (+S9) and Ames TA1535 (-S9) for all the isomers Ames test is negative therefore it is mutagen. The carcinogenicity for mouse is positive and carcinogenicity for rat is negative for IRPG molecule. In IRPG molecule, HERG inhibition is medium risk, Lipinski's rule is suitable, CMC-like rule is qualified, MDDR-like rule is Midstructure, Lead-like rule is suitable if its binding energy is greater than 0.1 microMol and WDI-like rule is within $90 \%$ cutoff. Consequently, the ADMET profiles clearly explain that the IRPG molecule is intermediate candidate for bioactive applications.

\section{Molecular docking analysis}

\section{Ligand preparation}

Utilizing Chemdraw8.0 software the IRPG 2D structure was drawn and this structure was converted into 3D structure via Chem3D ultra 8.0 programs [63]. Then the compound IRPG was optimized through Gaussian09W software using DFT method (basis set 6-311G(d,p)). Furthermore, the optimized structure is converted into PDB format and taken as a ligand. The docking analysis was performed via Autodock 4.2 software based on the steps followed in the literature [64]. 


\section{Protein preparation}

The protein structure of H1N1 NA and H3N2 NA enzyme was downloaded from RCSB protein data bank with the PDB id's of 3NSS (1.902 $\AA$ resolution) and 2AEP (2.1 $\AA$ resolution) respectively. From these proteins, the hetro-atoms such as ligand, ions and water molecules are removed from the H1N1 NA and H3N2 NA enzyme for docking process and taken as a target.

\section{Molecular docking}

Utilizing Autodock tools, the Kollman charges and polar hydrogen were added to the targets H1N1 NA and H3N2 NA enzyme. Grid parameter and docking parameter file are achieved by Autogrid and Autodock. Generic algorithm and LamarkianGA was used for probing the suitable conformers and score the ligand binding respectively. Therefore, the significance of docking process generates 10 conformers and it was represented in Table 10 , from these conformers $2^{\text {nd }}$ conformer is the best for H3N2 NA enzyme and $3^{\text {rd }}$ conformer is the best for H1N1 NA enzyme based on lowest binding energy. Moreover the lowest binding energy values are $-6.79 \mathrm{kcal} / \mathrm{mol}(\mathrm{H} 3 \mathrm{~N} 2 \mathrm{NA})$ and $-7.31 \mathrm{kcal} / \mathrm{mol}$ (H1N1 NA) with inhibition constant of 10.57 (H3N2 NA) and 4.41 (H1N1 NA) ki UM (micromol)) and this conformers is taken for further

process. Likewise, the intermolecular interactions of IRPG with H3N2 NA and H1N1 NA enzyme is analysed through Discovery Studio Visualizer, Chimera, PyMOL and Ligplot and are exposed in Fig. 9. Surface view of IRPG molecule embedded in H3N2 NA and H1N1 NA enzyme are shown in Fig. 10. Fig. 11 shows the Ligplot view of IRPG with H3N2 NA and H1N1 NA enzyme.

The interaction between IRPG with H1N1 NA enzyme reveals the lowest binding energy when compared with H3N2 NA enzyme. In IRPG-H1N1 NA complex the active site residues are Arg 118, Thr 148, Ile 149, Asp 151, Arg 371, Ser 404, Ile 427, Pro 431, Lys 432 and Glu 433. The Ile 149, Ser 404 and Glu 433 residues form strong conventional $\mathrm{H}$ bonding interactions with $\mathrm{H}(23), \mathrm{H}(24)$ and $\mathrm{H}(33)$ atoms at a distance of 2.05, 2.00 and $1.97 \AA$ respectively. The Pi-cation and Pi-Alkyl interactions form midst the residues center and ring center. The Pi-cation interactions form in-between $\operatorname{Arg} 118$ residue center and $2^{\text {nd }}$ ring center at a distance of $3.28 \AA$. Residues Ile 427 and Lys 432 forms Pi-Alkyl interactions with $1^{\text {st }}$ ring center at a distance of 4.23 and $4.34 \AA$ respectively. Residues Ile 149 and Pro 431 also form Pi-Alkyl interactions with $2^{\text {nd }}$ ring center at a distance of 5.43 and $5.31 \AA$ respectively. 
In IRPG-H3N2 NA complex the active site residues are Cys 124, Pro 126, Cys 129, Ser 411, Val 412 and Glu 413. The residues Pro 126 and Ser 411 form strong conventional H bonding interactions with $\mathrm{H}(23)$ and $\mathrm{H}(24)$ atoms at a distance of 1.87 and $2.26 \AA$ respectively. Residues Val 412 and Cys 129 form Pi-Alkyl interaction with $1^{\text {st }}$ and $2^{\text {nd }}$ ring at a distance of 4.46 and $4.09 \AA$ respectively. The Pi-Sulfur interaction form in-between the aromatic ring center and sulphur atom in residues. In IRPG-H3N2 NA complex Pi-sulfur interaction forms between $1^{\text {st }}$ ring and Cys 129 (S) and Cys 124 (S) at a distance of 5.81 and $5.32 \AA$ respectively. The Ligplot also confirms the same active site interactions values for IRPG-H3N2 NA and IRPG-H1N1 NA complexes. This result reveals that IRPG molecule is strongly embedded with H1N1 NA compare with H3N2 NA. Hence this interaction develops the binding affinity of IRPG towards H3N2 NA and H1N1 NA enzymes.

\section{Conclusion}

IRPG molecular structure was optimized to its minimum energy conformation and the computed parameters are compared with the experimental XRD data related to the structure, the values are coincide with optimized B3LYP/6-311G(d,p) basis set. The experimental and observed results of FT-IR and FTRaman are promising result with each other. In IRPG molecule the strong bands from HOMO to LUMO level appears in first major contributions of $\pi \rightarrow \pi^{*}$ transitions with 100\%. Mulliken charges and the MEP charges are parallel to IRPG and the map exemplifies that the negative regions are on oxygen atoms while the positive regions are on carbon and hydrogen atoms. The electrophilicity values for IRPG is found to be $3.062 \mathrm{eV}$, this value confirms that the molecule has less toxicity in nature. IRPG molecule falls under soft molecule category due to low band gap energy value (3.859 eV). Fukui function and NBO confirms that the IRPG molecule possess good chemical selectivity and high stability. IRPG molecule obeys the Lipinski's rule of five and bioactivity score values do not fall under the value less than -0.05 , therefore the molecule is a potential candidate for bioactive application. An ADMET prediction for IRPG obtains promising biological activity, this prediction helps to improve further drug design. The molecule IRPG enters in the active site cavity of H1N1 and H3N2 NA enzyme, large conformation modification takes place. The lowest binding energy and inhibition constant of IRPG in H1N1 NA enzyme reveals that powerful role when compared to IRPG in H3N2 NA enzyme. These results suggest that H1N1 NA is a potential inhibitor of influenza A virus and also it provides some key ideas for further development of anti-influenza drugs. 


\section{Declaration}

\section{Author statement}

All persons who meet authorship criteria are listed as authors, and all authors certify that they have participated sufficiently in the work to take public responsibility for the content, including participation in the concept, design, analysis, writing and revision of the manuscript. Furthermore, each author certifies that this material or similar material has not been and will not be submitted to or published in any other publication before its appearance in the journal 'Structural Chemistry'.

\section{Funding}

The author(s) received no financial support for the research, authorship, and/or publication of this article.

\section{Declaration of Competing Interest}

The authors declare that there are no conflicts of interest associated with this publication, has not been published before and not currently being considered for publication elsewhere.

\section{Code availability}

Not applicable.

\section{CRediT authorship contribution statement}

Sathya Bangaru: Conceptualization, Methodology, Software, Validation, Formal analysis, Investigation, Resources, Data curation, Writing - original draft, Writing - review \& editing, Visualization, Supervision, Project administration. Prasath Manivannan: Conceptualization, Methodology, Software, Validation, Formal analysis, Investigation, Resources, Data curation, Writing - original draft, Writing review \& editing, Visualization, Supervision, Project administration. Sivakumar Murugesan and Govindammal Madhu support this work.

\section{Ethics approval}

Not applicable.

\section{Consent to participate}

All the authors have given consent to participate. 


\section{Consent for publication}

All the authors have seen and approved the manuscript.

\section{References}

1. Wang Z, Cheng LP, Zhang XH, Pang W, Li L, Zhao JL (2007) Design, synthesis and biological evaluation of novel oseltamivir derivatives as potent neuraminidase inhibitors. Bioorg Med Chem Lett 27(24):5429-5435. https://doi.org/10.1016/j.bmcl.2017.11.003.

2. Dao TT, Nguyen PH, Lee HS, Kim E, Park J, Lim SI, Oh WK (2011) Chalcones as novel influenza A (H1N1) neuraminidase inhibitors from Glycyrrhiza inflate. Bioorg Med Chem Lett 21(1):294-298. https://doi.org/10.1016/j.bmcl.2010.11.016.

3. Murray CJL, Lopez AD, Chin B, Feehan D, Hill KK (2006) Estimation of potential global pandemic influenza mortality on the basis of vital registry data from the 1918-20 pandemic: a quantitative analysis. The Lancet 368(9554):2211-2218. https://doi.org/10.1016/S0140-6736(06)69895-4.

4. Goldrick BA, Goetz AM (2007) Pandemic influenza: What infection control professionals should know. Am J Infect Control 35(1):7-13. https://doi.org/10.1016/j.ajic.2006.04.203.

5. Flahault A, Vergu E, Coudeville L, Grais RF (2006) Strategies for containing a global influenza pandemic. Vaccine 24(44-46):6751-6755. https://doi.org/10.1016/j.vaccine.2006.05.079.

6. De Clercq E, Neyts Z (2007) Avian influenza A (H5N1) infection: targets and strategies for chemotherapeutic intervention, Trends Pharmacol Sci 28(6):280-285. https://doi.org/10.1016/j.tips.2007.04.005.

7. Oxford JS, Lambkin R, Elliot A, Daniels R, Sefton A, Gill D (2006) Scientific lessons from the first influenza pandemic of the 20th century. Vaccine 24(44-46):6742-6746. https://doi.org/10.1016/j.vaccine.2006.05.101.

8. Moscona A (2005) Neuraminidase Inhibitors for Influenza. N Engl J Med 353(13):1363-1373. https://doi.org/10.1056/NEJMra050740.

9. Zhu Z, Li R, Xiao G, Chen Z, Yang J, Zhu Q, Liu S (2012) Design, synthesis and structureeactivity relationship of novel inhibitors against H5N1 hemagglutinin-mediated membrane fusion. Eur J Med Chem 57:211-216. https://doi.org/10.1016/j.ejmech.2012.08.041. 
10. Verma RP, Hansch C (2006) QSAR study on influenza neuraminidase inhibitors. Bioorganic \& Medicinal Chemistry. Bioorg Med Chem 14(4):982-996. https://doi.org/10.1016/j.bmc.2005.09.016.

11. Sakudo A, Baba K, Tsukamoto M, Sugimoto A, Okada T, Kobayashi T, Kawashita N, Takagi T, Ikuta K (2009) Anionic polymer, poly(methyl vinyl ether-maleic anhydride)-coated beads-based capture of human influenza A and B virus. Bioorg Med Chem 17:752-757. https://doi.org/10.1016/j.bmc.2008.11.046.

12. McKimm Breschkin JL, Barrett S, Pilling PA, Hader S, Watts AG, Streltsov VA (2018) Structural and Functional Analysis of Anti-Influenza Activity of 4-, 7-, 8- and 9-Deoxygenated 2,3-Difluoro-Nacetylneuraminic Acid Derivatives. J Med Chem 61(5):1921-1933. https://doi.org/10.1021/acs.jmedchem.7b01467.

13. Li Y, Lin Z, Zhao M, Xu T, Wang C, Hua L, Wang H, Xia H, Zhu B (2016). ACS Appl Mater Interfaces. 8(37):24385-24393. https://doi.org/10.1021/acsami.6b06613.

14. Nair PC, Sobhia ME (2008) Quantitative structure activity relationship studies on thiourea analogues as influenza virus neuraminidase inhibitors. Eur J Med Chem 43(2):293-299. https://doi.org/10.1016/j.ejmech.2007.03.020.

15. Fang Y, Yu Y, Hou Q, Zheng X, Zhang M, Zhang D, Li J, Wu X-R, Huang C (2012) The Chinese Herb Isolate Isorhapontigenin Induces Apoptosis in Human Cancer Cells by Down-regulating Overexpression of Antiapoptotic Protein XIAP. J Biologic Chem 287(42):3523435243. https://doi.org/10.1074/jbc.M112.389494.

16. Grienke U, Schmidtke M, Von Grafenstein S, Kirchmair J, Liedlc KR, Rollinger JM (2012) Influenza neuraminidase: A druggable target for natural products. Nat Prod Rep 29(1):11-36. https://doi.org/10.1039/c1np00053e.

17. Frisch MJ, Trucks GW, Schlegel HB, Scuseria GE, Robb MA, Cheeseman JA, Calmani G, Barone V, Mennucci B, Petersson GA, Nakatsuji H, Caricato M, Li X, Izmaylov AF Hratchian, Bloino J, Zheng G, Sonnenberg JL, Hada M, Ehara M, Toyota K, Fukuda R, Hasegawa J, Ishida M, Nakajima T, Honda Y, Kitao O, Nakai H, Vreven T, Montgomery JA Jr, Peralta JE, Ogliaro F, Bearpark M, Heyd JJ, Brothers E, Kudin KN, Staroverov VN, Keith T, Kobayashi R, Normand J, Raghavachari K, Rendell A, Burant JC, Iyengar SS, Tomasi J, Cossi M, Rega N, Millam JM, Klene M, Knox JE, Cross 
JB, Bakken V, Adamo C, Jaramillo J, Gomperts R, Stratmann RE, Yazyev O, Austin AJ, Cammi R, Pomelli C, Ochterski JW, Martin RL, Morokuma K, Zakrzewski VG, Voth GA, Salvador P, Dannenberg JJ, Dapprich S, Daniels AD, Farkas O, Foresman JB, Ortiz JV, Cioslowski J, Fox DJ (2010). Gaussian 09, Revision B.01, Gaussian, Inc., Wallingford CT.

18. Frisch E, Hratchian HP, Dennington RD II, et al., (2009). Gaussview, Version 5.0.8, 235, Gaussian, Inc., Wallingford, C.T.

19. Jamróz MH (2013) Vibrational Energy Distribution Analysis (VEDA): Scopes and limitations. Spectrochim Acta Part A Mol Biomol Spectrosc 114:220-230. https://doi.org/10.1016/j.saa.2013.05.096.

20. Stash A, Tsirelson V (2002) WinXPRO: a program for calculating crystal and molecular properties using multipole parameters of the electron density. J Appl Crystallogr 35(3):371-373. https://doi.org/10.1107/S0021889802003230.

21. Marques MAL, Maitra NT, Nogueira FMS, Gross EKU, Rubio A, editors (2012) Fundamentals of Time-Dependent Density Functional Theory (Springer Berlin Heidelberg, Berlin, Heidelberg,). Lecture Notes in Physics 837. https://doi.org/10.1007/978-3-642-23518-4.

22. CASIDA ME (1995). Time-Dependent Density Functional Response Theory for Molecules. $155-192$. https://doi.org/10.1142/9789812830586_0005.

23. Jorge M. Seminario, editor (1996). Time-Dependent Density Functional Response Theory for Molecular Systems: Theory, Computational Methods, and Functionals. In Recent Developments and Applications of Modern Density Functional Theory, Theoretical and Computational Chemistry (Elsevier B. V, Amsterdam).

24. Glendening ED, Reed AE, Carpenter JE, Weinhold F, NBO Version 3.1.

25. Morris GM, Huey R, Lindstrom W, Sanner MF, Belew RK, Goodsell DS, Olson AJ (2009) AutoDock4 and AutoDockTools4: Automated docking with selective receptor flexibility. J Comput Chem 30(16):2785-2791. https://doi.org/10.1002/jcc.21256.

26. Dassault Syst_emes BIOVIA, Discovery Studio, (2016). DS2016Client32, SanDiego: Dassault Syst_emes.

27. Pettersen EF, Goddard TD, Huang CC, Couch GS, Greenblatt DM, Meng EC, Ferrin TE (2004) UCSF 
Chimera?A visualization system for exploratory research and analysis. J Comput Chem 25(13):16051612. https://doi.org/10.1002/jcc.20084.

28. The PyMOL Molecular Graphics System, Version 1.8 Schrodinger, LLC.

29. Laskowski RA, Swindells MB (2011) LigPlot+: Multiple Ligand-Protein Interaction Diagrams for Drug Discovery. J Chem Inf Model 51(10): 2778-2786. https://doi.org/10.1021/ci200227u.

30. Labanowski JK, Andzelm JW, editors (1991) Density Functional Methods in Chemistry (Springer New York, New York, NY). 1-443. https://doi.org/10.1007/978-1-4612-3136-3.

31. Parr WYRG (1989) Density Functional Theory of Atoms and Molecules (Oxford University Press, New York, NY).

32. Bartosz Zarychta, Christopher G. Gianopoulos, Alan Pinkerton A (2016) Revised structure of transresveratrol: Implications for its proposed antioxidant mechanism. Bioorg Med Chem Lett 26(5):14161418. https://doi.org/10.1016/j.bmcl.2016.01.070.

33. Zubatyuk RI, Shishkin OV, Gorb L, Leszczynski J (2009) Homonuclear versus Heteronuclear Resonance-Assisted Hydrogen Bonds: Tautomerism, Aromaticity, and Intramolecular Hydrogen Bonding in Heterocyclic Systems with Different Exocyclic Proton Donor/Acceptor. J Phys Chem A 113(12):2943-2952, https://doi.org/10.1021/jp8100859.

34. NIST Computational Chemistry Comparison and Benchmark Database, NIST Standard Reference Database Number 101, Release 19, April 2018, Editor: Russell D. Johnson III. http://cccbdb.nist.gov/.

35. Pielesz A, Biniaś D, Wieczorek J (2011) FT-IR spectroscopic analysis in monitoring of hydroxyl stretching vibrations in plant hydrogels. Polim Med 41(4):33-42. http://www.ncbi.nlm.nih.gov/pubmed/22332324.

36. Bellamy LJ (1975) The Infra-Red Spectra of Complex Molecules (Springer Netherlands, Dordrecht). https://doi.org/10.1007/978-94-011-6017-9.

37. Kalsi PS (2002) Spectroscopy of Organic Compounds (Academic Press, New York, NY).

38. Chalasinski G, Szczesniak MM (1994) Origins of Structure and Energetics of van der Waals Clusters from ab Initio Calculations. Chem. Rev. 94(7):1723-1765. https://doi.org/10.1021/cr00031a001.

39. Varsanyi G (1969) Vibrational Spectra of Benzene Derivative (Academic Press, New York, NY). 
40. Choperena A, Painter P (2009) An infrared spectroscopic study of hydrogen bonding in ethyl phenol: A model system for polymer phenolics. Vib Spectrosc 51(1):110-118. https://doi.org/10.1016/j.vibspec.2008.11.008.

41. Scrocco E, Tomasi J (1978). Electronic Molecular Structure, Reactivity and Intermolecular Forces: An Euristic Interpretation by Means of Electrostatic Molecular Potentials. Advances in Quantum Chemistry. 115-193. https://doi.org/10.1016/S0065-3276(08)60236-1.

42. Sen K, Murray JS (1996) Molecular Electrostatic Potentials: Concepts and Applications, Elsevier B (Amsterdam).

43. Politzer P, Murray JS (2002) The fundamental nature and role of the electrostatic potential in atoms and molecules Theor Chem Accounts: Theory, Comput Model (Theoretica Chim Acta) 108(3):134142. https://doi.org/10.1007/s00214-002-0363-9.

44. Sathya B, Prasath M (2019) Spectroscopic (FT-IR, FT-Raman, UV-Vis), quantum chemical calculation and molecular docking evaluation of liquiritigenin: an influenza A (H1N1) neuraminidase inhibitor. Res Chem Intermed 45:2135-2166. https://doi.org/10.1007/s11164-018-03727-7.

45. Sathya B, Karthi S, Ajaijawahar K, Prasath M (2020) Probing the vibrational spectroscopic properties and binding mechanism of anti-influenza agent Liquiritin using experimental and computational studies. Res Chem Intermed 46:4475-4507. https://doi.org/10.1007/s11164-020-04216-6.

46. Sathya B, Prasath M, Muthu S (2020) Spectroscopic investigations, quantum chemical calculations and molecular docking studies of Mangiferin - an anti-viral agent of H1N1 Influenza virus. Chemical Data Collections. 30:100580. https://doi.org/10.1016/j.cdc.2020.100580.

47. Sathya B, Prasath M (2021) Probing the structural properties, binding mode and intermolecular interactions of herbacetin against H1N1 neuraminidase using vibrational spectroscopic, quantum chemical calculation and molecular docking studies. Res Chem Intermed https://doi.org/10.1007/s11164-021-04408-8.

48. Muthu S, Prasath M, Arun Balaji R (2013) Experimental and theoretical investigations of spectroscopic properties of 8-chloro-1-methyl-6-phenyl-4H-[1,2,4]triazolo[4,3-a][1,4]benzodiazepine, Spectrochim Acta A Mol Biomol Spectro. 106:129-145. http://dx.doi.org/10.1016/j.saa.2012.12.057 
49. Koopmans T (1934) Über die Zuordnung von Wellenfunktionen und Eigenwerten zu den Einzelnen Elektronen Eines Atoms. Physica 1(1-6):104-113. https://doi.org/10.1016/S0031-8914(34)90011-2.

50. Pauling L, Wheland GW (1934) The Nature of the Chemical Bond. V. J Chem Phys 2(8):482-482. https://doi.org/10.1063/1.1749514.

51. Mulliken RS (1955) Electronic Population Analysis on LCAO [Single Bond] MO Molecular Wave Functions. I. J Chem Phys 23(10):1833-1840. https://doi.org/10.1063/1.1740588.

52. Parr RG, Pearson RG (1983) Absolute hardness: companion parameter to absolute electronegativity J Am Chem Soc 105(26):7512-7516 https://doi.org/10.1021/ja00364a005.

53. Parr RG, Szentpály LV, Liu S (1999) Electrophilicity Index. J Am Chem Soc 121(9):1922-1924. https://doi.org/10.1021/ja983494x.

54. Sathya B, Prasath M, Selvapandiyan M, Prabha K (2019) Vibrational Analysis (FT-IR and FT-Raman Spectra) and Molecular Docking Evaluation of MPTB in GABA Receptor J Clust Sci 30:1025-1035. https://doi.org/10.1007/s10876-019-01562-3.

55. Roy DR, Sarkar U, Chattaraj PK, Mitra A, Padmanabhan J, Parthasarathi R, Subramanian V, Van Damme S, Bultinck P (2006) Analyzing Toxicity Through Electrophilicity. Mol Divers 10(2),119131. https://doi.org/10.1007/s11030-005-9009-x.

56. Yang W, Parr RG (1985) Hardness, softness, and the fukui function in the electronic theory of metals and catalysis. Proc Natl Acad Sc. 82(20):6723-6726. https://doi.org/10.1073/pnas.82.20.6723.

57. Padmanabhan J, Parthasarathi R, Elango M, Subramanian V, Krishnamoorthy BS, Gutierrez-Oliva S, Toro-Labbé A, Roy DR, Chattaraj PK (2007) Multiphilic Descriptor for Chemical Reactivity and Selectivity J Phys Chem A 111(37):9130-9138. https://doi.org/10.1021/jp0718909.

58. Weinhold CRLF (2005) Valency and Bonding: A Natural Bond Orbital Donor Acceptor Perspective (Cambridge University Press, Cambridge).

59. Lipinski CA, Lombardo F, Dominy BW, Feeney PJ (2001) Experimental and computational approaches to estimate solubility and permeability in drug discovery and development settings. Adv Drug Deliv Rev 46(1-3):3-26. https://doi.org/10.1016/S0169-409X(00)00129-0.

60. Alodeani EA, Arshad M, Izhari MA (2015) Anti-uropathogenic activity, drug likeness, physicochemical and molecular docking assessment of (E-)-N'-(substituted-benzylidene)-2-(quinolin- 
8-yloxy) acetohydrazide. Asian Pac J Trop Biomed 5(8):676-683. https://doi.org/10.1016/j.apjtb.2015.04.010.

61. Di L, Kerns EH (2016) Drug-Like Properties: Concepts, Structure Design and Methods from ADME to Toxicity Optimization (Elsevier). https://doi.org/10.1016/C2013-0-18378-X.

62. Kramer C, Ting A, Zheng H, Hert J, Schindler T, Stahl M, Robb G, Crawford JJ, Blaney J, Montague S, Leach AG, Dossetter AG, Griffen EJ (2017) Learning Medicinal Chemistry Absorption, Distribution, Metabolism, Excretion, and Toxicity (ADMET) Rules from Cross-Company Matched Molecular Pairs Analysis (MMPA). J Med Chem 61(8):3277-3292. https://doi.org/10.1021/acs.jmedchem.7b00935.

63. Mendelsohn LD (2004) ChemDraw 8 Ultra, Windows and Macintosh Versions. J. Chem. Inf. Comput. Sci. 44(6):2225-2226. https://doi.org/10.1021/ci040123t.

64. Rizvi SMD, Shakil S, Haneef M (2013) A simple click by click protocol to perform docking: AutoDock 4.2 made easy for non-bioinformaticians. EXCLI J 12:831-857. http://www.ncbi.nlm.nih.gov/pubmed/26648810. 
Figures

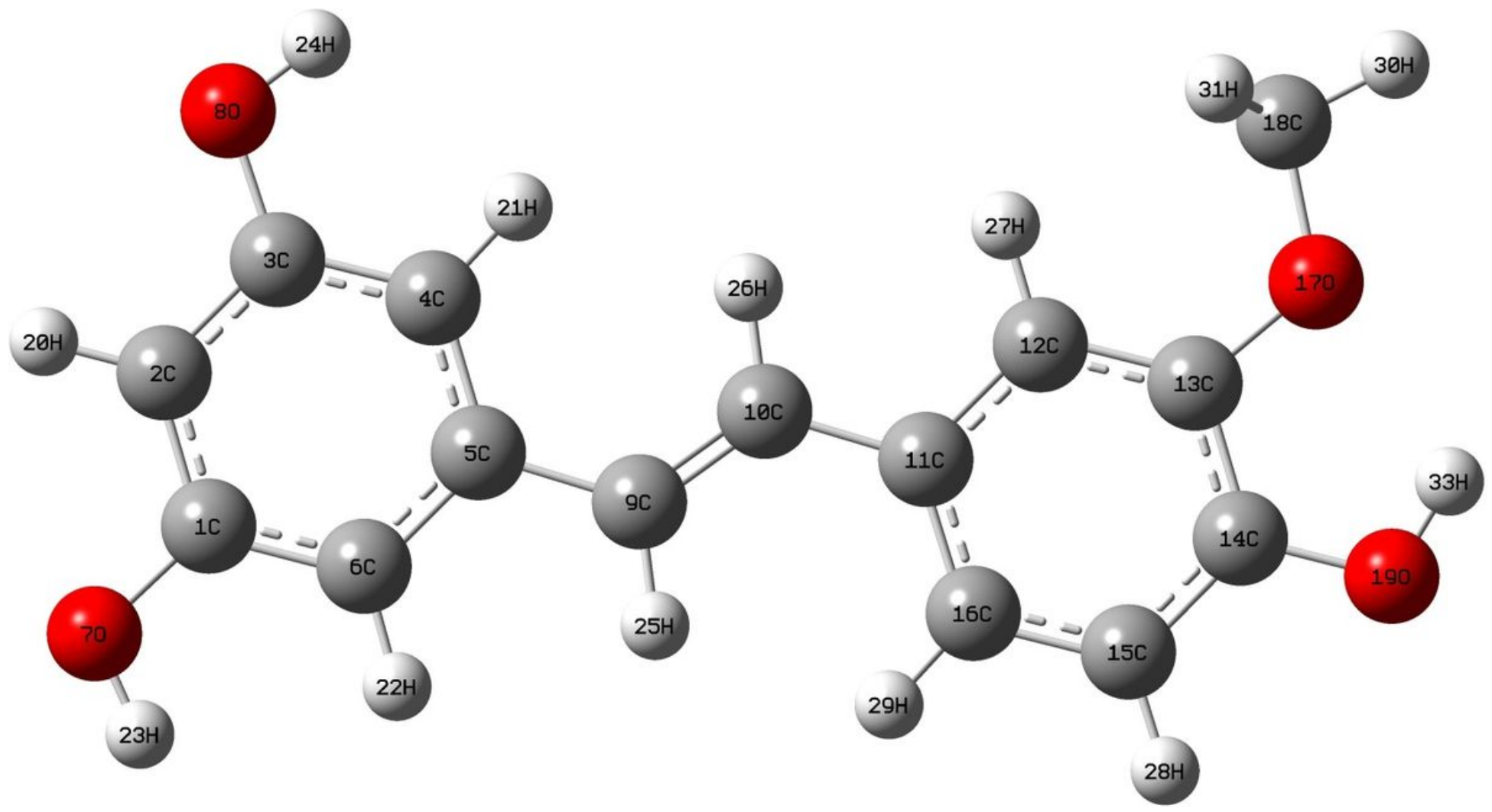

Figure 1

The ball and stick model of optimized structure of IRPG with atom numbering scheme 


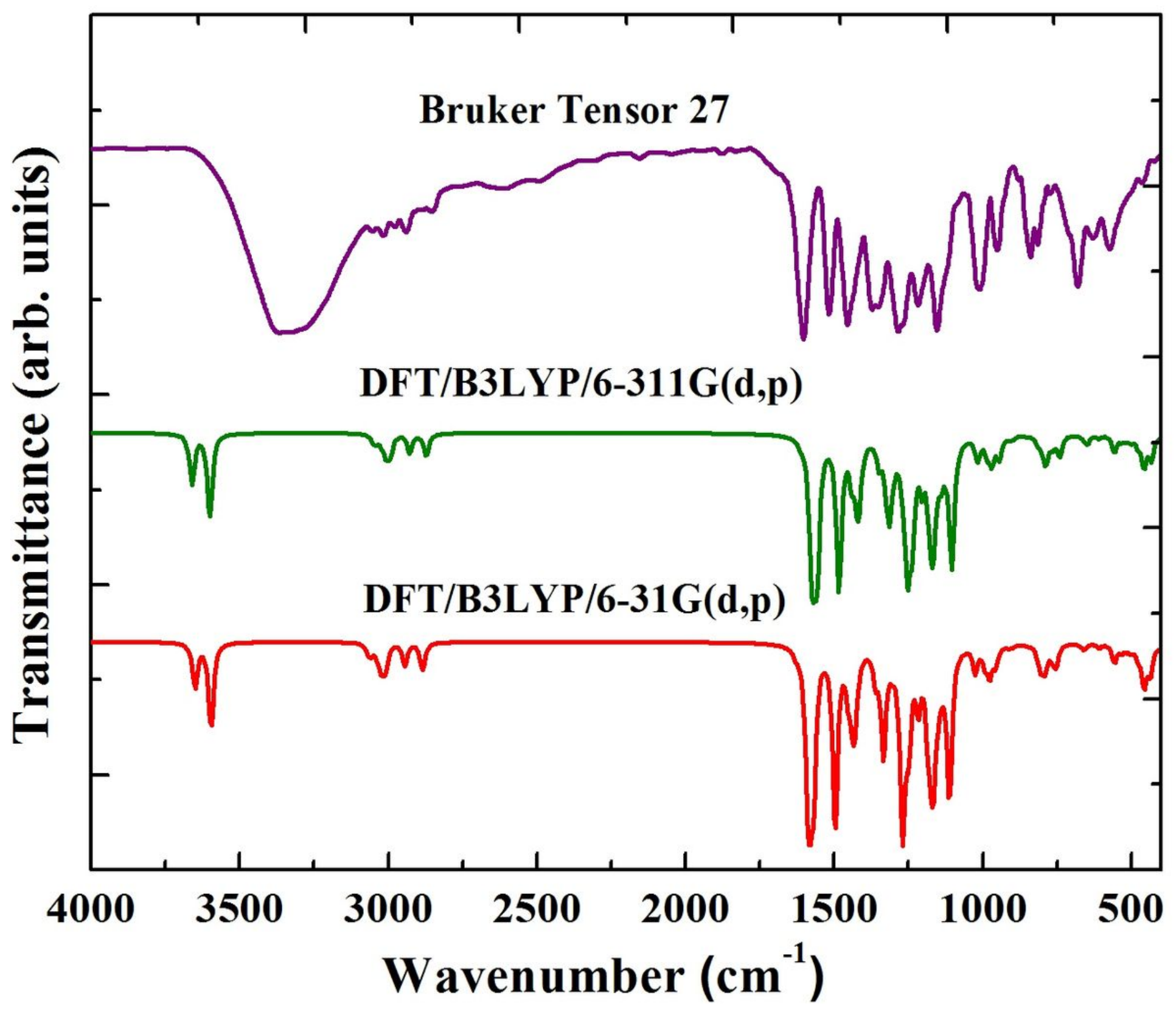

Figure 2

Experimental (Violet) and theoretical (Green-B3LYP/6-311G(d,p), Red-B3LYP/6-31G(d,p)) FT-IR spectra of IRPG 


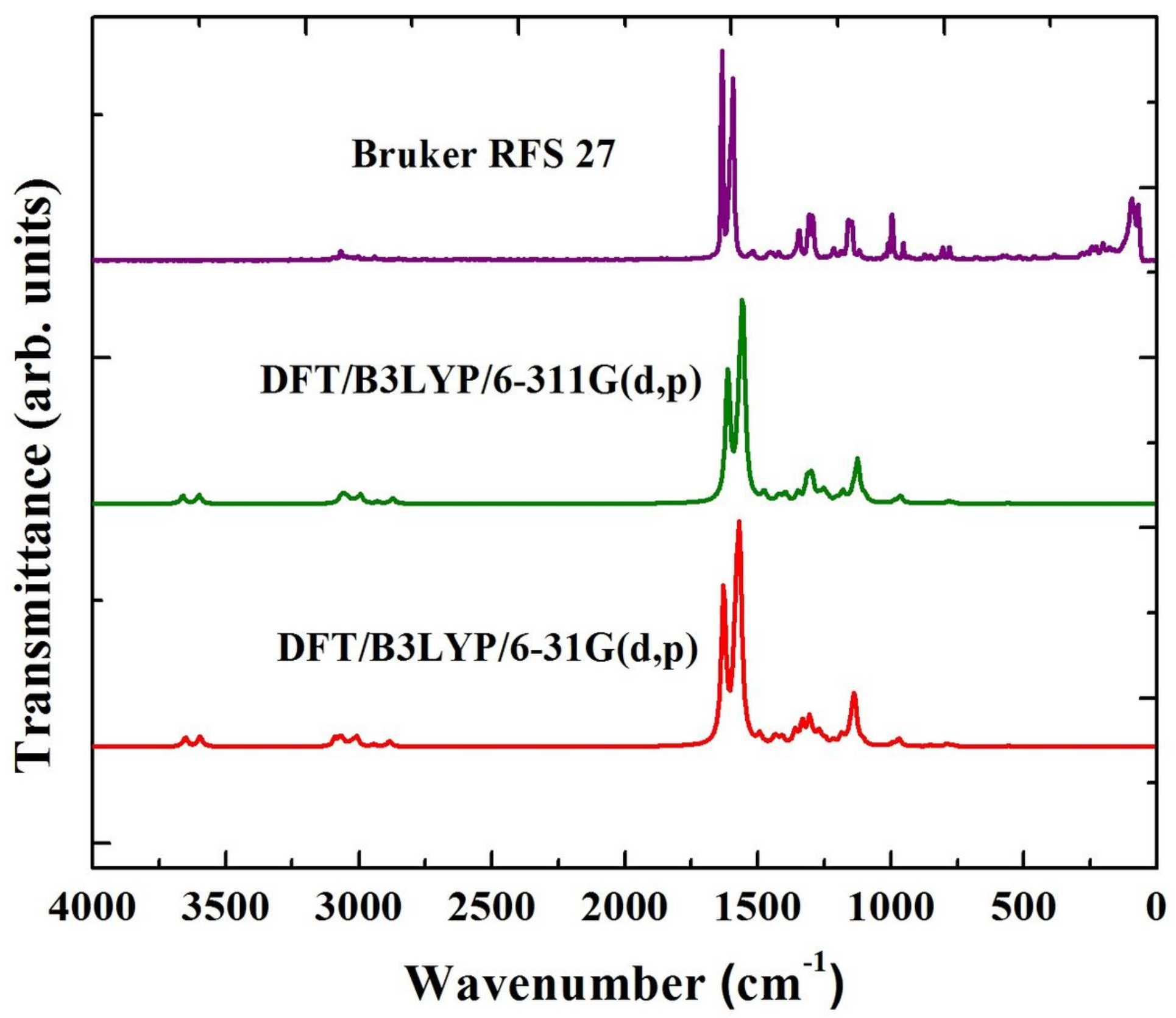

Figure 3

Experimental (Violet) and theoretical (Green-B3LYP/6-311G(d,p), Red-B3LYP/6-31G(d,p)) FT-Raman spectra of IRPG 


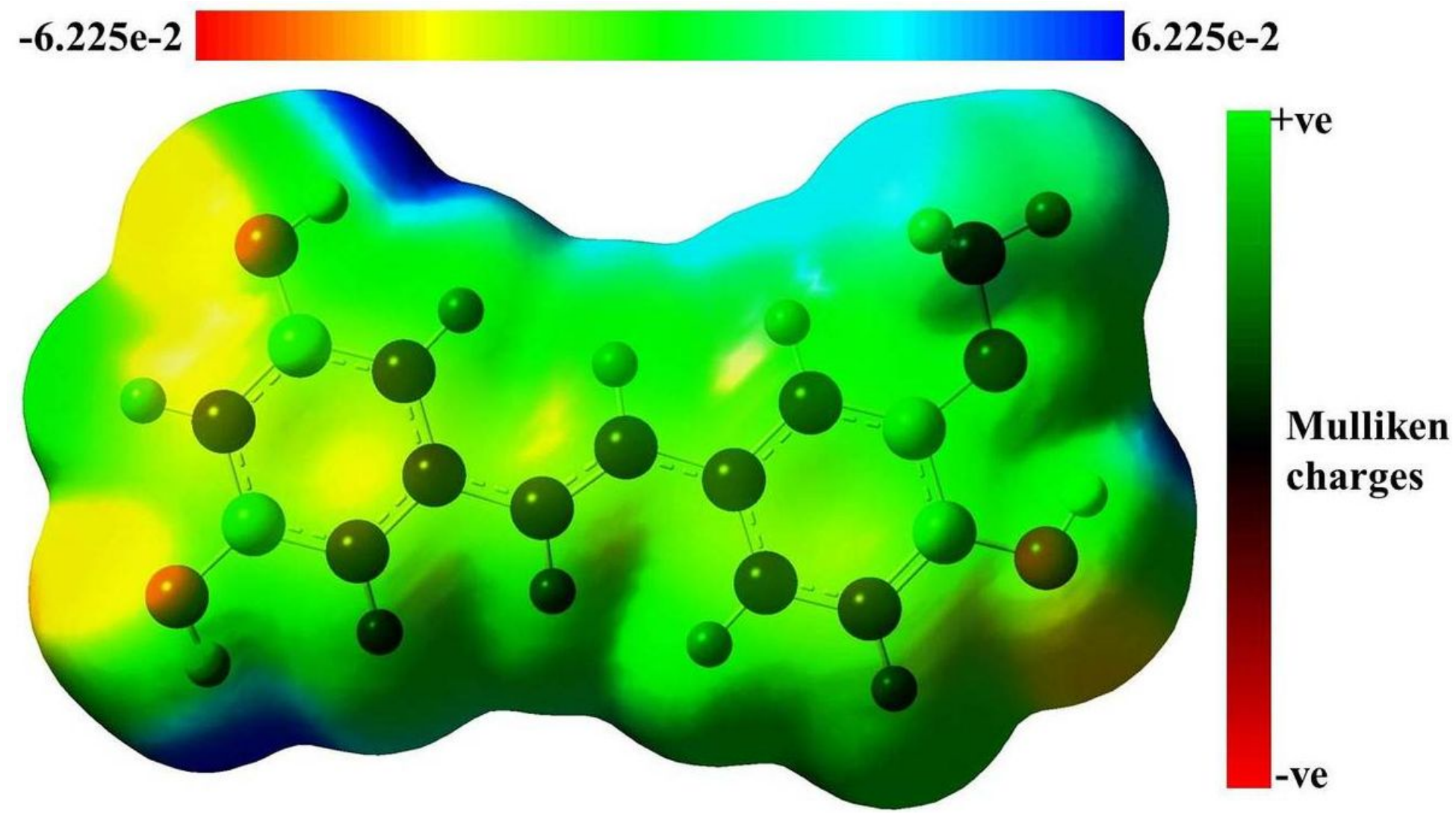

Figure 4

Molecular electrostatic potential map of IRPG coloured on the basis of Mulliken atomic charges

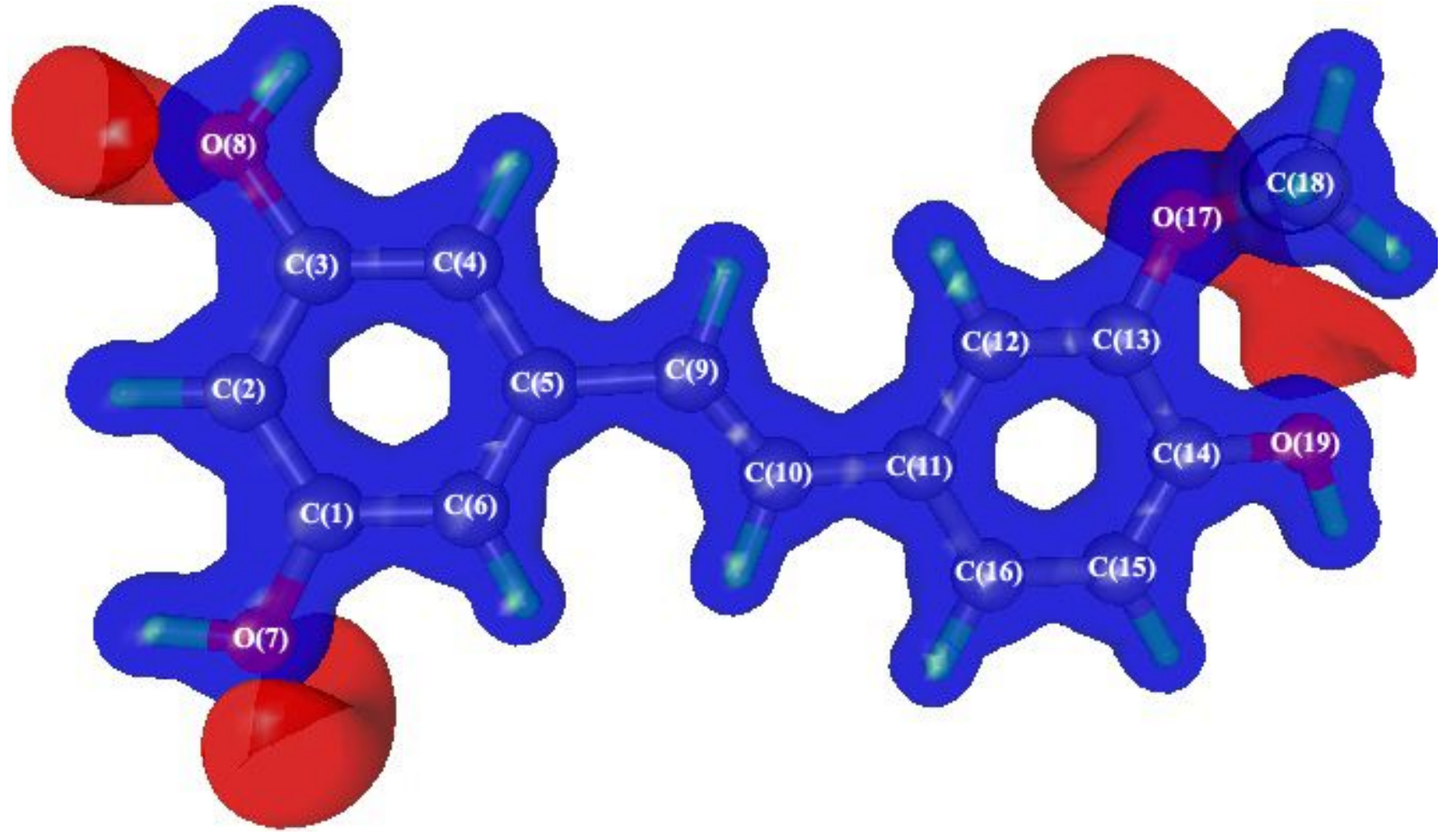

Figure 5 
Molecular electrostatic potential map of IRPG molecule showing the electropositive (blue) and electronegative (red) regions of the molecule, the Iso surface values are positive potential at $0.8 \mathrm{e} \AA-1$ and negative potential at $0.08 \mathrm{e} \AA-1$

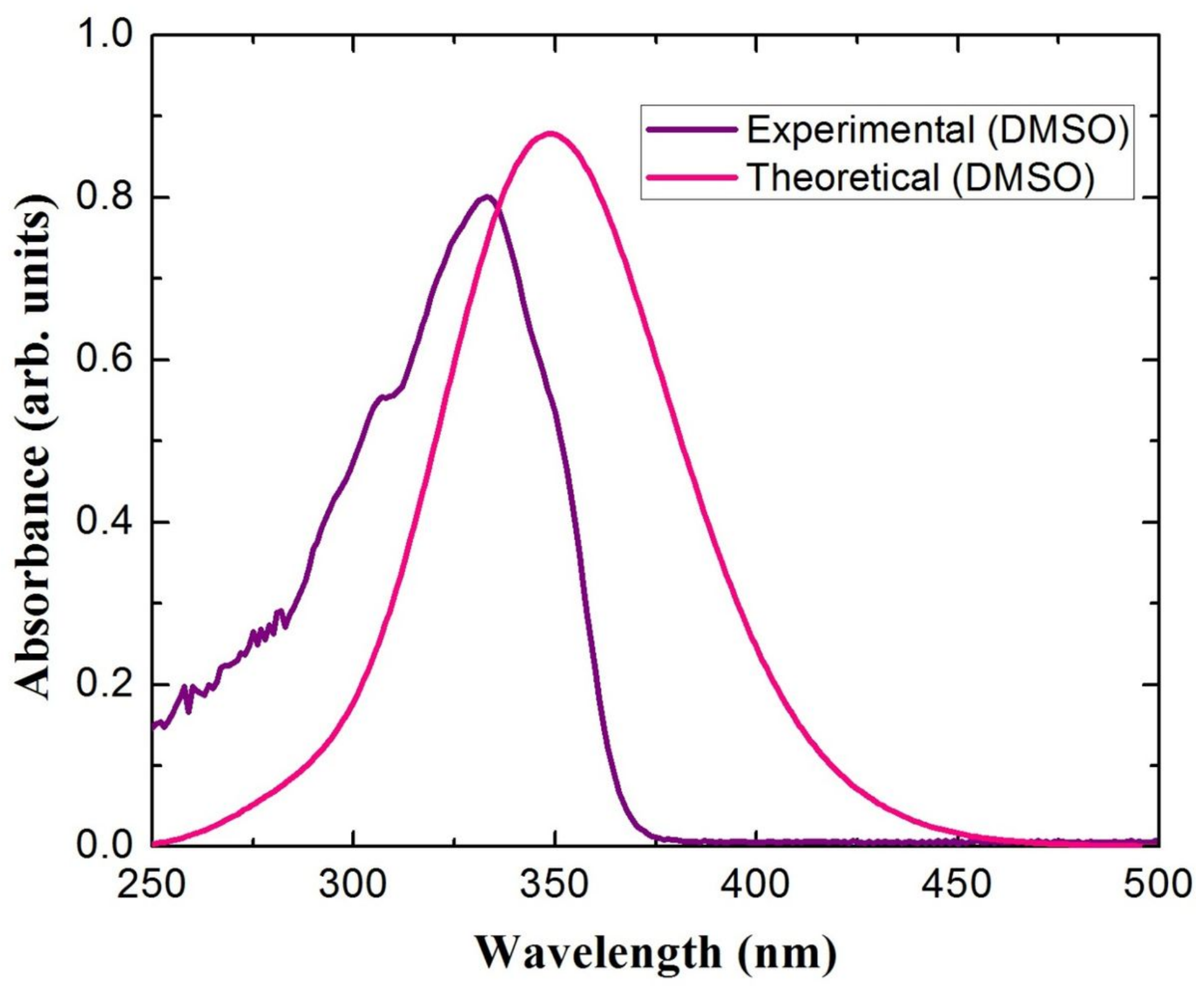

Figure 6

Experimental and theoretical absorption spectra of IRPG in DMSO solution 


\section{LUMO Plot First Excited State}

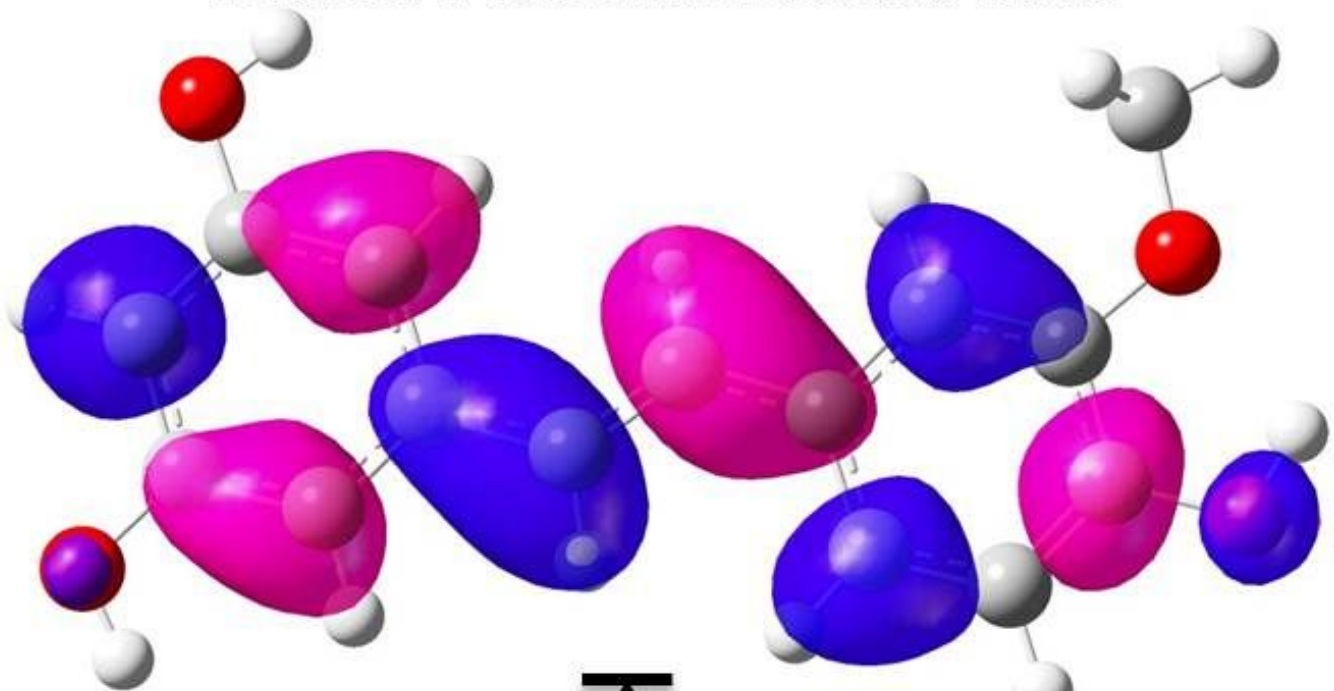

$\mathbf{E}_{\text {номо }}=\mathbf{- 5 . 3 6 8 \mathrm { eV }}$

$E_{g}=3.859 \mathrm{eV}$

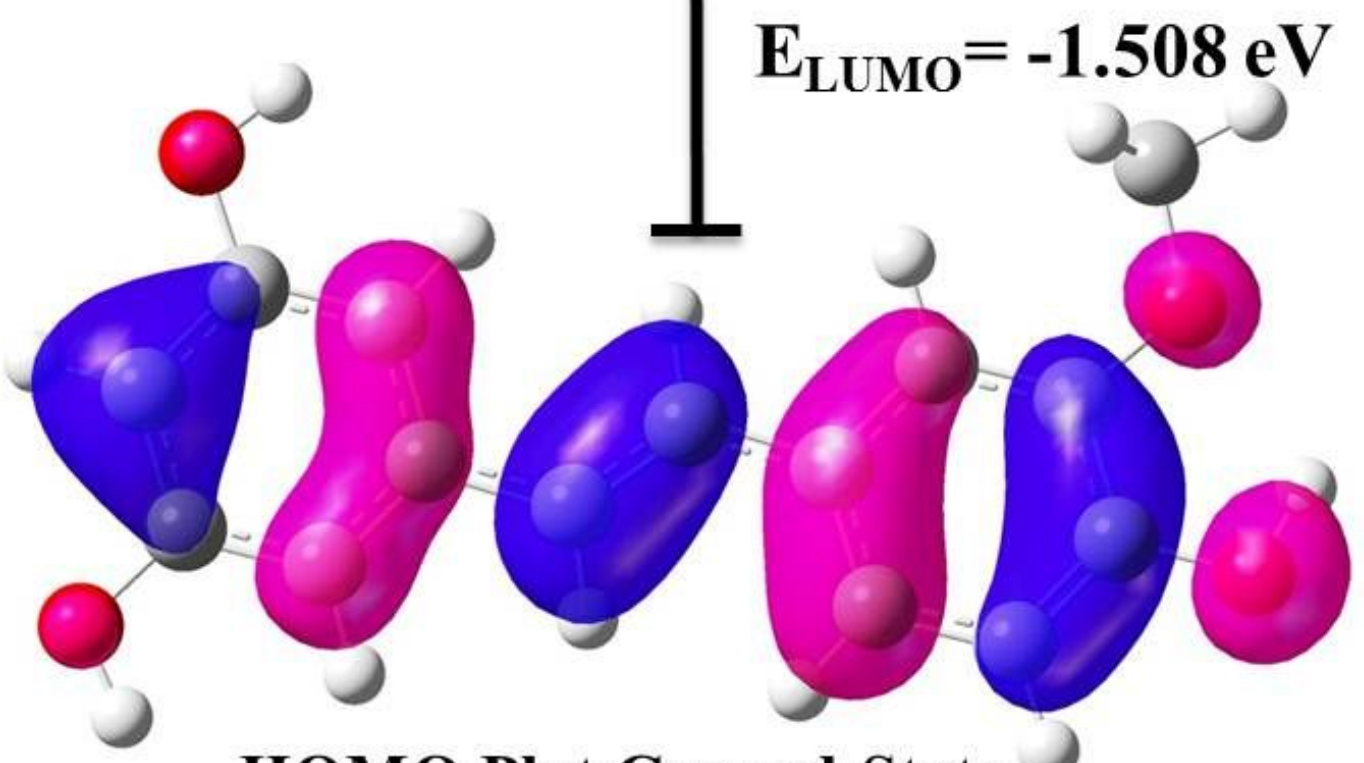

HOMO Plot Ground State

Figure 7

The HOMO and LUMO orbitals of IRPG 


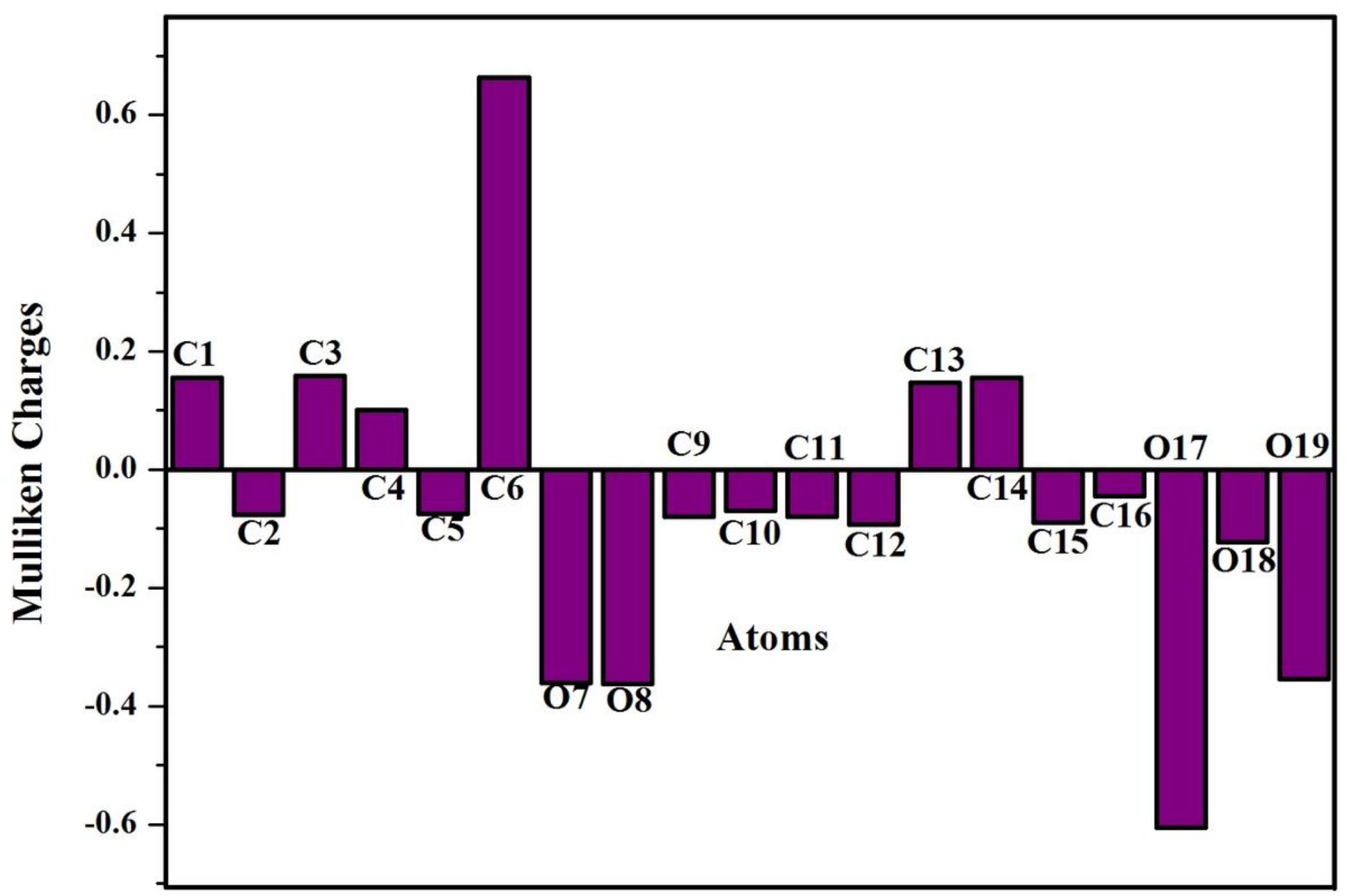

Figure 8

The histogram of computed Mulliken charge of IRPG molecule expects hydrogen atoms
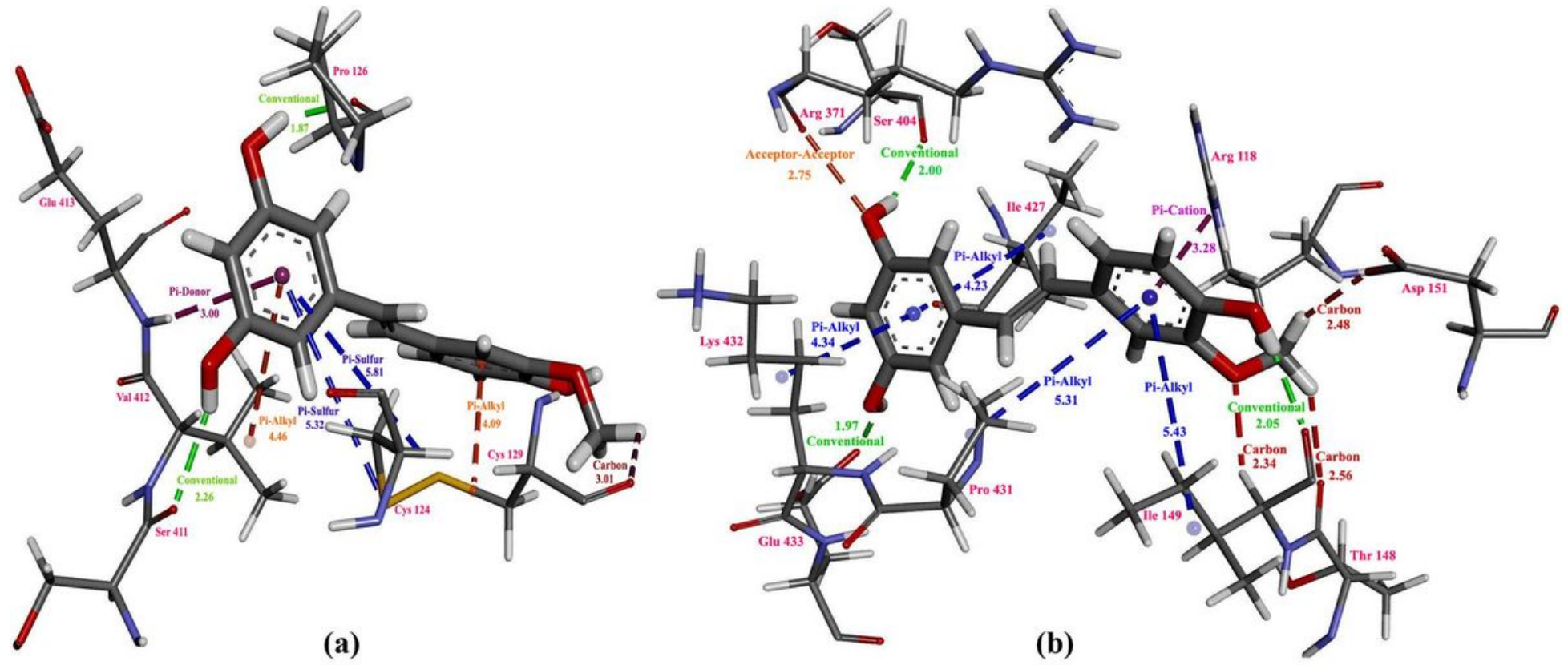

Figure 9 
Intermolecular interactions of IRPG with (a) H3N2 NA and (b) H1N1 NA enzyme

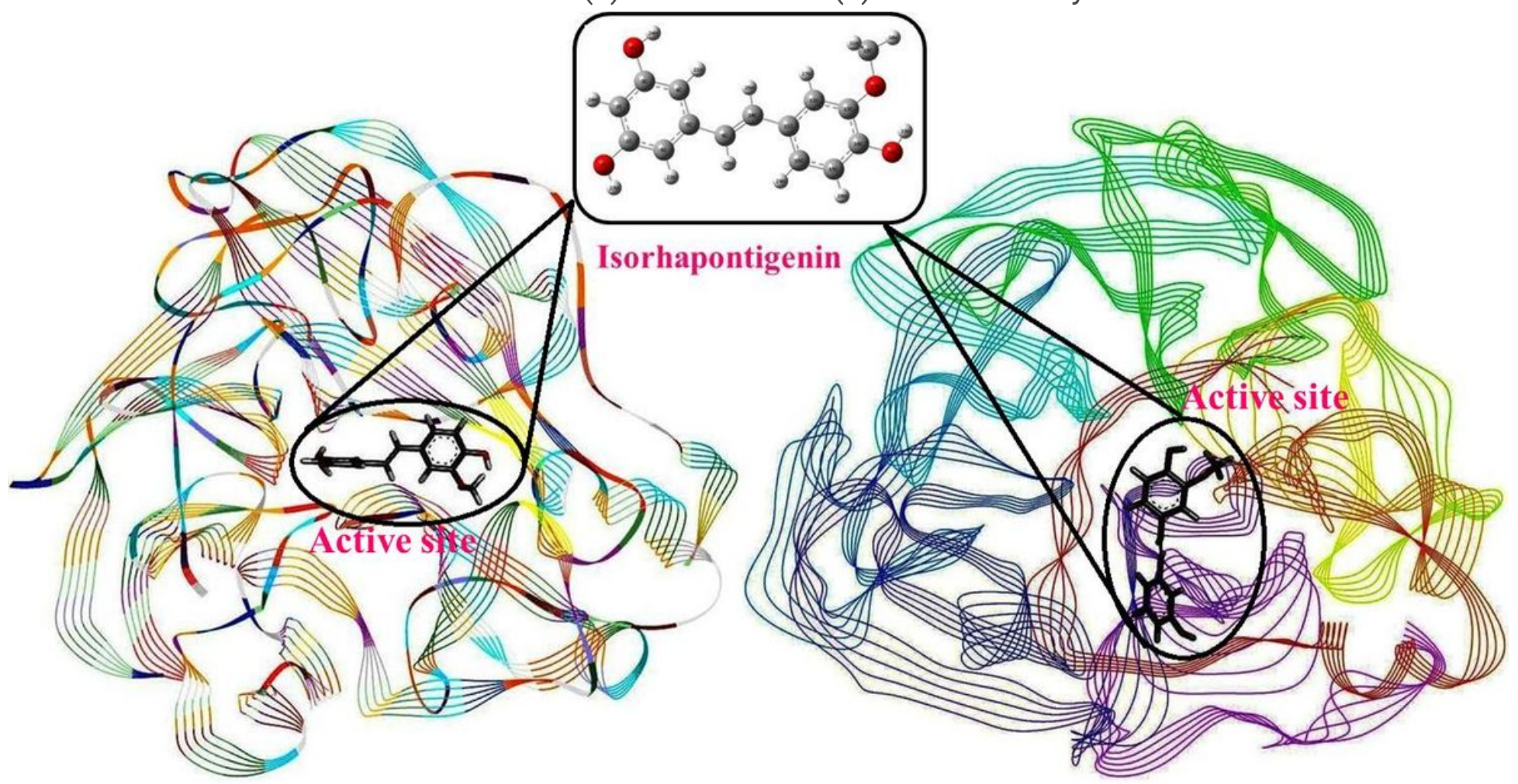

(a)

(b)

Figure 10

Surface view of IRPG encapsulated in the active site of (a) H3N2 NA and (b) H1N1 NA enzyme 


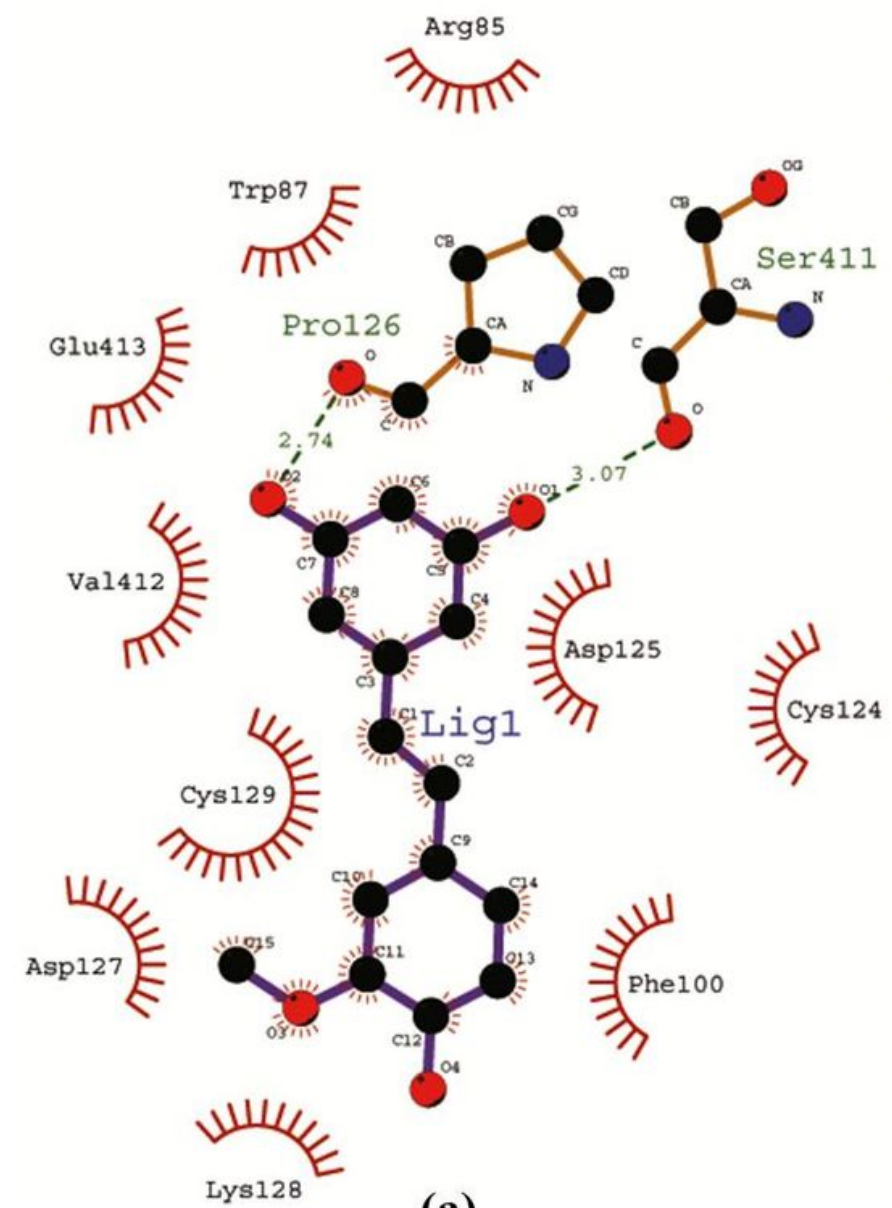

(a)

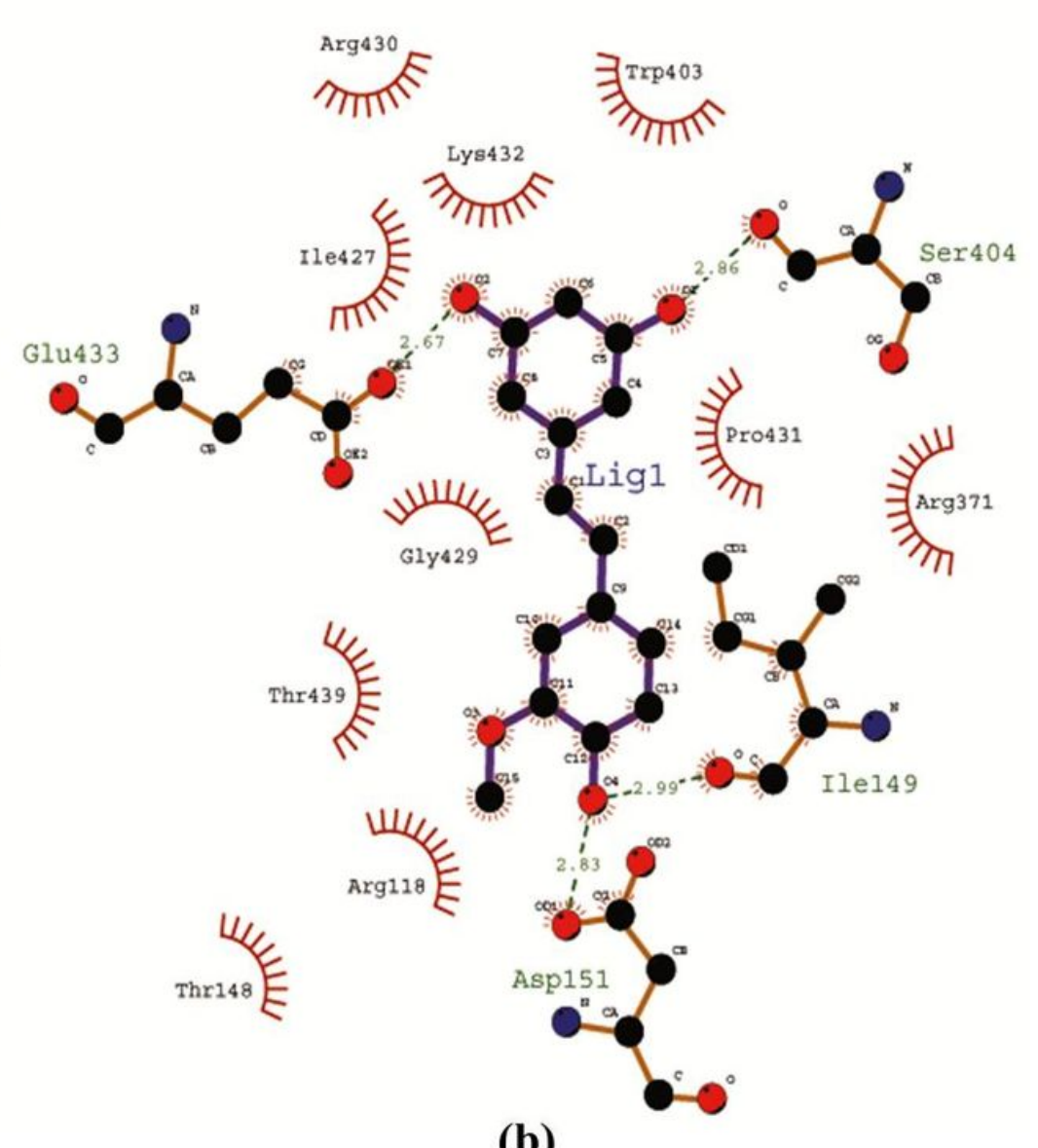

(b)

\section{Figure 11}

The ligplot showing intermolecular interactions of IRPG in the active site of (a) H3N2 NA and (b) H1N1 NA enzyme 